\title{
Kajian Etnomatematika Pola Batik Keraton Surakarta Melalui Analisis Simetri
}

\author{
Maria Glory Astriandini $^{1}$ dan Yosep Dwi Kristanto ${ }^{2 *}$ \\ Program Studi Pendidikan Matematika, Universitas Sanata Dharma \\ Paingan, Maguwoharjo, Depok, Sleman, Indonesia \\ 1glory.nyus24@gmail.com; ${ }^{2 *}$ yosepdwikristanto@usd.ac.id
}

Artikel diterima: 18-08-2020, direvisi: 27-01-2021, diterbitkan: 31-01-2021

\begin{abstract}
Abstrak
Etnomatematika memberikan peluang pengkajian batik dari dua sudut pandang, yaitu kebudayaan dan matematika. Kajian seperti ini akan memberikan dampak yang positif dalam pembelajaran matematika karena peserta didik difasilitasi untuk belajar matematika dengan menggunakan pengetahuan budaya yang relevan dan berbagai macam cara berpikir tentang matematika. Tujuan penelitian ini adalah untuk melakukan kajian etnomatematika pada batik Keraton Surakarta yang digunakan dalam upacara tradisi dengan menggunakan analisis simetri. Metode penelitian yang digunakan dalam penelitian ini adalah metode kualitatif deskriptif. Dari hasil analisis diperoleh 11 batik yang memiliki pola simetri. Pola simetri yang muncul dari kesebelas batik tersebut adalah $p 1$, $p 2, p 4 m$, dan pgg. Selain itu, penelitian ini juga memasangkan pola-pola simetri tersebut dengan makna filosofis batik-batiknya. Dengan demikian, melalui kajian etnomatematika, penelitian ini memberikan kontribusi pedagogis terhadap pembelajaran matematika.

Kata Kunci: batik, etnomatematika, kristalografi, simetri
\end{abstract}

\section{Ethnomathematics Study on the Pattern of Surakarta Palace Batik Through Symmetry Analysis}

\begin{abstract}
Ethnomatematics provides opportunities to study batik from two perspectives, namely culture and mathematics. The study will have a positive impact on mathematics teaching and learning because students are facilitated to learn mathematics by using relevant cultural knowledge and various ways of thinking about mathematics. The purpose of the present study is to conduct an ethnomathematics study on the Keraton Surakarta batik which is used in traditional ceremonies by applying symmetry analysis. The present study employed a descriptive qualitative method. From the analysis, we found that 11 batiks have symmetry patterns. The symmetry patterns are $p 1, p 2$, $p 4 m$, dan pgg. Besides, the present study also connects the symmetry patterns with the corresponding batik's philosophical meaning. Therefore, through ethnomathematics, the present study gives pedagogical contributions to mathematics teaching and learning.

Keyword: batik, ethnomathematics, crystallography, symmetry
\end{abstract}




\section{Pendahuluan}

Kebudayaan merupakan hal yang melekat dalam kehidupan manusia. Kebudayaan merupakan entitas yang kompleks (Chao \& Moon, 2005). Kebudayaan memuat hasil karya manusia, seperti pengetahuan, kesenian, hukum, kepercayaan, dan lain sebagainya. Karena pola pikir dan kebiasaan masyarakat satu sama lain yang beragam, maka keberagaman budaya juga dijumpai antara masyarakat satu dengan yang lainnya.

Setiap daerah di Indonesia memiliki kebudayaan yang berbeda-beda. Salah satu budaya Indonesia yang tidak lekang oleh zaman adalah batik. Batik ini mengandung beragam simbol-simbol yang terkait dengan status sosial seseorang, identitas masyarakat, serta sejarah dan warisan budaya. Oleh karena itu, batik telah ditetapkan oleh UNESCO sebagai warisan kemanusiaan untuk budaya lisan dan nonbendawisejak tahun 2009 (UNESCO, 2009).

Daerah-daerah di Indonesia mempunyai cara masing-masing untuk menggambarkan identitas dan budayanya dalam batik yang tergambar pada gaya dan bentuknya. Salah satunya adalah Keraton Surakarta. Penciptaan batik keraton pada waktu itu difungsikan sebagai pakaian upacara ritual (Pujiyanto, 2013). Oleh karena itu, banyak upacara ritual atau tradisi di lingkungan keraton menggunakan kain batik dengan motif-motif tertentu, misalnya upacara kelahiran, pernikahan, hingga upacara kematian (duka). Lebih jauh, Pujiyanto (2013) berpendapat bahwa batik tidak hanya enak dipandang, tetapi juga memberi makna yang erat hubungannya dengan falsafah hidup, pesan dan harapan tulus membawa kebaikan dan kebahagiaan bagi yang memakainya.

Selain makna filosofis, batik juga memiliki kekayaan motif atau corak yang tidak luput dari kajian para peneliti. Salah satu teknik analisis yang cukup sering digunakan untuk mengkaji motif batik adalah analisis simetri (Garnadi et al., 2012; Maulidya \& Sihombing, 2018). Analisis simetri ini memungkinkan batik untuk dianalisis secara matematis. Dengan demikian, sudut pandang matematika ini akan memperkaya pemaknaan batik sebagai bentuk kebudayaan dan menempatkannya dalam konteks pembelajaran matematika secara formal, informal, ataupun nonformal. Hal ini sejalan dengan etnomatematika.

Etnomatematika adalah kajian atau program penelitian yang menyelidiki sejarah, antropologi, pedagogi, bahasa, dan filosofi matematika dengan implikasi pedagogis yang berfokus pada menjelaskan, memahami, dan menghadapi lingkungan sosio-budaya yang beragam (Rosa \& Gavarrete, 2017; Lisnani, dkk., 2020). Etnomatematika paling tidak memiliki dua tujuan (Albanese et al., 2017). Pertama, program ini bertujuan untuk mengenali ide dan praktik beberapa kelompok budaya (Barton, 1996). Kedua, program ini juga bertujuan untuk menemukan macam-macam cara untuk 
mengetahui kuantitas, ruang, dan relasi yang dilakukan oleh beberapa kelompok budaya (D'Ambrosio, 2012). Karena dua tujuan etnomatematika ini, hasil kajian program tersebut dapat digunakan dalam pembelajaran matematika agar proses pembelajarannya memiliki konteks budaya yang relevan dengan pengetahuan dan pengalaman awal peserta didik. Selain itu, hasil kajian etnomatematika tersebut dapat memberikan wawasan bagi peserta didik tentang berbagai macam cara atau sudut pandang dalam memaknai matematika.

Kajian etnomatematika memberikan peluang bagi kebudayaan, khususnya batik, untuk digunakan dalam pembelajaran matematika. Oleh karena itu, banyak penelitian yang melakukan kajian etnomatematika pada batik ('Adna et al., 2020; Faiziyah et al., 2021; Mulyani \& Natalliasari, 2020). Meskipun demikian, masih diperlukan kajian etnomatematika dari sudut pandang yang beragam terhadap batik. Salah satunya adalah teknik yang telah disinggung sebelumnya, yaitu analisis simetri. Analisis simetri ini masih jarang dilakukan untuk melakukan kajian etnomatematika terhadap batik, khususnya batik Keraton Surakarta.

Berdasarkan uraian yang telah dipaparkan sebelumnya, tujuan penelitian ini adalah untuk melakukan kajian etnomatematika pada batik Keraton Surakarta yang digunakan dalam upacara tradisi dengan menggunakan analisis simetri. Untuk mencapai tujuan tersebut, penelitian ini memiliki dua pertanyaan penelitian.

(1) Pola simetri apa saja yang dimiliki oleh batik-batik Keraton Surakarta yang digunakan dalam upacara tradisi?

(2) Makna filosofi apa yang dimiliki oleh batik-batik yang memiliki pola simetri?

Simetri yang digunakan dalam penelitian ini merupakan simetri bidang. Konsep simetri ini juga disebut dengan isometri atau transformasi geometri yang kaku. Empat jenis transformasi masuk ke dalam simetri, yaitu pergeseran, rotasi, refleksi, dan pantul geser. Analisis simetri dapat digunakan untuk mengkategorikan polapola geometris menjadi desain terhingga (dimensi nol), dimensi satu, dan dimensi dua. Karena motif batik pada umumnya masuk ke dalam kategori pola dimensi dua, maka kami hanya akan memfokuskan ke pembahasan pola dimensi dua.

Berdasarkan kajian Crowe (2004), total terdapat 17 pola dimensi dua. Pembagian pola-pola dimensi dua tersebut didasarkan pada adanya pergeseran, rotasi, refleksi, dan pantul geser. Selanjutnya kami akan akan mendeskripsikan pola-pola tersebut berdasarkan klasifikasi Crowe (Crowe, 2004). Jika sebuah pola dalam dimensi dua tidak memiliki rotasi terkecil, maka kemungkinan kategorinya adalah $\mathrm{cm}, \mathrm{pm}$, $p g$, dan $p 1$. Pola cm memiliki sumbu refleksi dan sumbu pantul geser yang berbeda dengan sumbu refleksinya, sedangkan pm memiliki sumbu refleksi tetapi tidak memiliki sumbu pantul geser yang berbeda dengan sumbu refleksinya. Sebagai 
ilustrasi, contoh pola $\mathrm{cm}$ dan $\mathrm{pm}$ ditunjukkan pada Gambar 1. Pola pg dan $p 1$ sama-sama tidak memiliki sumbu refleksi. Bedanya, pg memiliki sumbu pantul geser sedangkan $p 1$ tidak memilikinya.

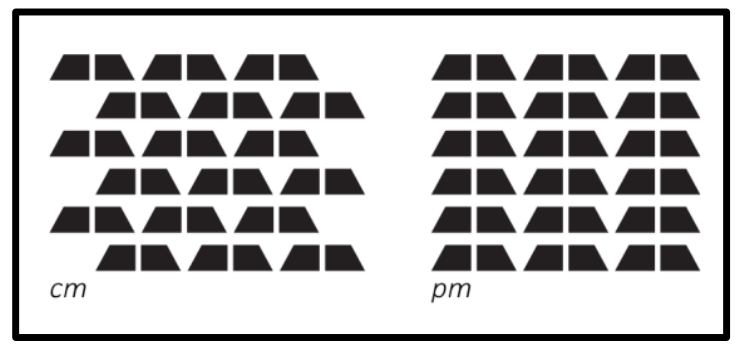

Gambar 1. Contoh Pola $\mathrm{cm}$ dan $\mathrm{pm}$

Terdapat lima kategori pola yang rotasi terkecilnya sebesar $180^{\circ}$, yaitu $\mathrm{pmm}, \mathrm{cmm}$, pmg, pgg, dan p2. Pola pmm memiliki sumbu refleksi, refleksi dua arah, dan rotasi yang semuanya berpusat di sumbu refleksinya. Pola $\mathrm{cmm}$ hampir sama dengan pmm, tetapi pusat rotasi pada pola ini tidak semuanya berada di sumbu refleksinya. Pola pmg memiliki sumbu refleksi, tetapi refleksi tidak dalam dua arah. Pola pgg dan p2 sama-sama tidak memiliki sumbu refleksi, tetapi pgg juga memiliki sumbu pantul geser sedangkan p2 tidak memilikinya.

Tiga kategori pola memiliki rotasi terkecil sebesar $90^{\circ}$, yaitu $p 4 m, p 4 g$, dan $p 4$. Pola-pola $p 4 m$ dan $p 4 g$ memiliki sumbu refleksi, sedangkan pola $p 4$ tidak memilikinya. Perbedaan $p 4 m$ dan $p 4 g$ terletak pada sumbu refleksinya. Pola $p 4 m$ sumbu-sumbu simetrinya berpotongan dan membentuk sudut $45^{\circ}$, sedangkan sumbu simetri pola $p 4 m$ tidak demikian.
Terdapat tiga pola yang memiliki rotasi terkecil $120^{\circ}$, yaitu $p 3 m 1, p 31 m$, dan $p 3$. Pola $p 3 m 1$ memiliki sumbu refleksi dan semua pusat rotasinya berada di sumbu refleksi tersebut. Pola p31m memiliki sumbu refleksi, tetapi tidak semua pusat refleksinya berada di sumbu refleksi tersebut. Pola p3 tidak memiliki sumbu refleksi.

Dua pola memiliki rotasi terkecil $60^{\circ}$, yaitu $p 6 m$ dan $p 6$. Meskipun demikian, kedua pola ini memiliki perbedaan terkait ada tidaknya sumbu refleksi. Pola $p 6 m$ memiliki sumbu refleksi, sedangkan $p 6$ tidak memiliki sumbu refleksi.

\section{Metode}

Penelitian ini menggunakan metode deskriptif kualitatif (Sandelowski, 2000). Data yang digunakan untuk menjawab pertanyaan-pertanyaan penelitian adalah data hasil observasi, wawancara, dan dokumentasi. Data dikumpulkan dengan teknik observasi lapangan, wawancara dan dokumentasi. Observasi dilakukan untuk mendapatkan informasi mengenai batik Keraton Surakarta secara langsung di tempat penelitian, wawancara dilakukan guna mendapatkan informasi mengenai sejarah dan filosofi batik dari pihak museum, dan dokumentasi digunakan untuk mengambil gambar kain batik Keraton Surakarta yang dimiliki oleh musem. Narasumber wawancara dalam penelitian ini adalah asisten manager museum batik Danar Hadi Solo. 


\section{Analisis data dilakukan dengan} menggunakan teknik analisis data kualitatif yang diusulkan oleh Miles dkk. (2014). Teknik ini memuat tiga langkah utama, yaitu reduksi data, penampilan data, dan penarikan kesimpulan. Pada tahap reduksi data, kami meringkas data hasil observasi lapangan, wawancara, dan dokumentasi agar dapat menjawab pertanyaanpertanyaan penelitian. Ringkasan data tersebut terdiri dari data yang berkaitan filosofi tiap motif batik dan jenis batik Keraton Surakarta yang digunakan dalam upacara tradisi yang berpola simetri.

Pada tahap penampilan data, kami menampilkan data hasil reduksi secara deskriptif. Penampilan data ini diawali dengan pendeskripsian ragam batik pola simetri apa saja yang terdapat pada kain batik Keraton Surakarta yang digunakan dalam upacara tradisi. Selanjutnya, motif kain batik Keraton Surakarta tersebut diidentifikasi dan dianalisis pola simetrinya dengan menggunakan diagram alur polapola simetri dua dimensi (Crowe, 2004). Setelah pola simetri masing-masing batik teridentifikasi, selanjutnya filosofi masingmasing batik tersebut dideskripsikan.

Penarikan kesimpulan merupakan tahap terakhir dari analisis data. Pada tahap ini, kami menarik kesimpulan dari hasil penampilan data yang sesuai dengan pertanyaan penelitian dan tujuan penelitian. Tahap ini menghasilkan informasi pola simetri apa saja yang terdapat pada beberapa motif kain batik Keraton Surakarta yang digunakan dalam upacara tradisi berdasarkan pengelompokan pola simetrinya sehingga dapat dilihat kajian matematika di dalamnya, serta filosofi apa saja yang terkandung dari setiap motif batik tersebut.

\section{Hasil dan Pembahasan}

Berdasarkan data yang terkumpul, kami mendapatkan 19 batik Keraton Surakarta yang digunakan dalam upacara tradisi mulai dari lahir sampai meninggal. Dari 19 batik tersebut, 11 di antaranya memiliki pola simetri. Proporsi batik-batik yang memiliki pola simetri dan yang tidak memiliki pola simetri ditunjukkan pada Gambar 2.

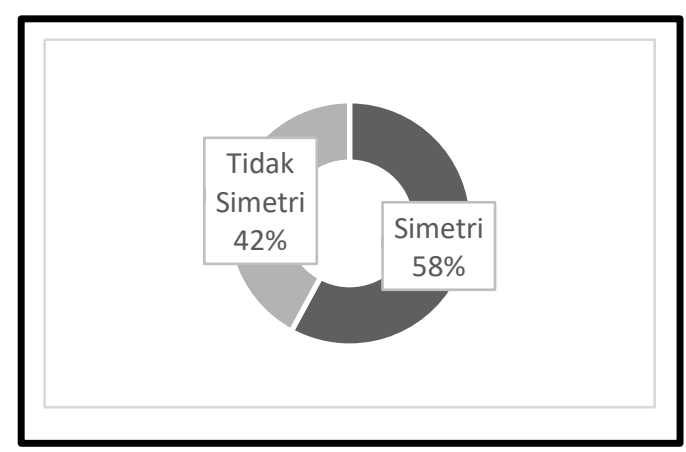

Gambar 2. Proporsi Batik Berpola Simetri

Sebelas batik dalam penelitian ini memiliki pola simetri di dalam motifnya. Kesebelas batik ini selanjutnya dianalisis pola simetri dan filosofi yang terkandung di dalamnya.

\section{A. Pola Simetri}

Terdapat 11 batik yang memiliki pola simetri. Pola simetri yang dimiliki oleh kesebelas batik tersebut masuk ke dalam kategori $p 1, p 2, p 4 m$, dan pgg.Pola simetri yang paling banyak dimiliki oleh batik-batik 
tersebut adalah $p 1$ dan $p 4 m$, sedangkan pola yang paling sedikit adalah $p 2$. Distribusi batik beserta dengan pola simetrinya ditunjukkan pada Gambar 3.

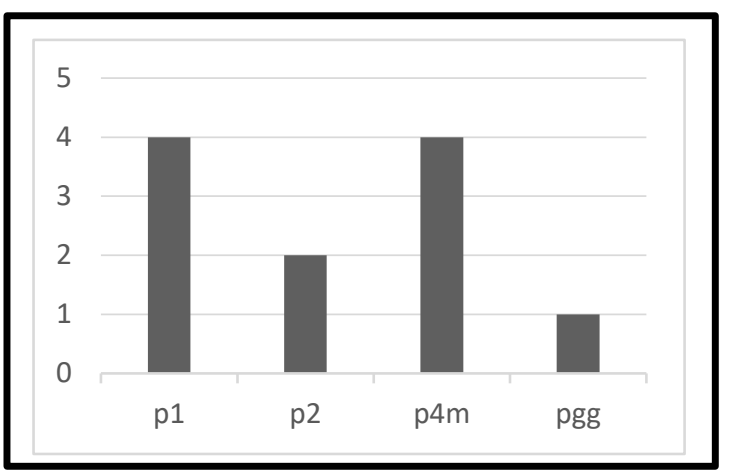

Gambar 3. Distribusi Pola Simetri Batik

Batik-batik yang memiliki pola simetri $p 1$ adalah batik Wirasat, batik Sidamukti, batik Sidaasih, dan batik Sidamulya. Pola $p 1$ ini tidak memiliki rotasi, refleksi, ataupun pantul geser. Sebagai ilustrasi, pola ini ditunjukkan oleh pola simetri batik Sidamukti yang ditunjukkan Gambar 4. Motif batik tersebut diperoleh dengan menggeser secara berulang pola dasarnya, yang ditunjukkan oleh segiempat berwarna hijau, dengan menggunakan dua vektor translasi: vektor pertama adalah vektor yang berwarna biru dan vektor kedua berwarna kuning.

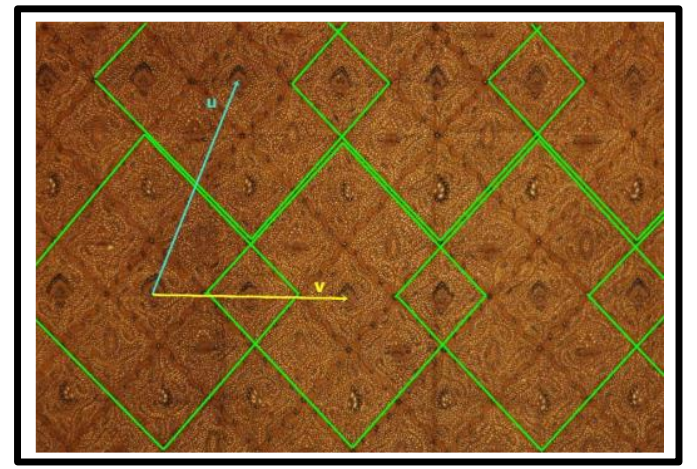

Gambar 4. Analisis Pola Simetri Batik Sidamukti
Pola kedua adalah p2. Pola ini dimiliki oleh batik Parang Pamor dan batik Parang Canthel. Pola kedua batik ini memiliki rotasi, tetapi tidak memiliki sumbu refleksi maupun pantul geser. Kedua pola dalam batik ini sama-sama memiliki rotasi terkecil sebesar $180^{\circ}$. Sebagai ilustrasi, analisis simetris motif batik Parang Canthel ditunjukkan oleh Gambar 5. Pusat rotasi motif batik tersebut ditunjukkan oleh noktah berwarna kuning. Sinar berwarna hijau dan biru menunjukkan vektor translasi motif tersebut.

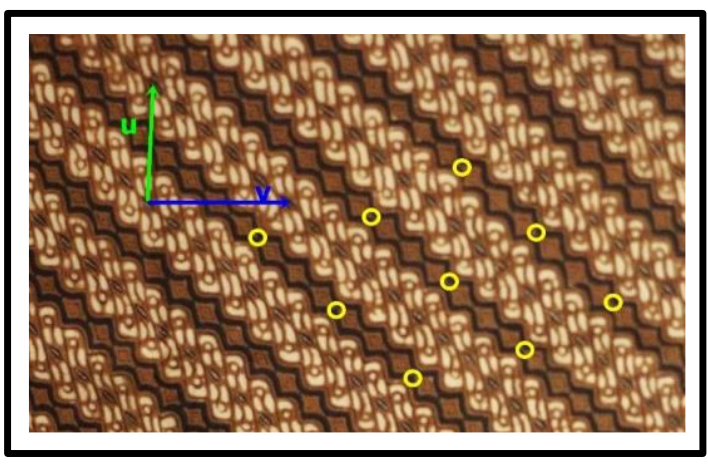

Gambar 5. Analisis Pola Simetri Batik Parang Canthel

Pola simetri ketiga adalah $p 4 m$. Pola ini merupakan salah satu pola yang paling banyak dimiliki oleh batik-batik yang dikaji dalam penelitian ini. Batik-batik yang memiliki pola tersebut adalah batik Nitik Cakar, batik Ceplok Satriya Wibawa, batik Truntum, dan batik Lurik Yuyu Sekandang. Motif keempat batik tersebut memiliki rotasi terkecil $90^{\circ}$ dan refleksi. Sumbusumbu refleksi keempat motif batik tersebut berpotongan pada sudut yang besarnya $45^{\circ}$. Sebagai contoh, Gambar 6 menunjukkan motif batik Nitik Cakar. Motif 
batik tersebut memiliki pusat rotasi pada noktah berwarna merah dan sumbu-sumbu simetri yang ditunjukkan oleh garis-garis yang berwarna hijau dan kuning.

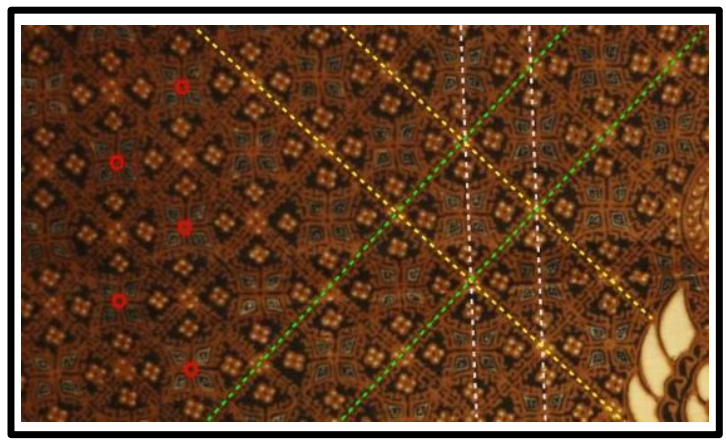

Gambar 6. Analisis Simetri Batik Nitik Cakar

Pola simetri terakhir yang dimiliki oleh batik-batik dalam penelitian ini adalah pgg. Batik yang memiliki pola ini adalah batik Slobog. Kedua batik ini memiliki rotasi terkecil $180^{\circ}$ dan pantul geser, tetapi tidak memiliki refleksi. Sebagai contoh, Gambar 7 berikut menunjukkan motif batik Slobog beserta dengan pusat rotasi dan sumbu pantul gesertanya. Pada gambar tersebut, pusat rotasi ditunjukkan dengan noktah merah, sedangkan sumbu-sumbu pantul gesernya ditunjukkan oleh garis-garis yang berwarna biru dan kuning.

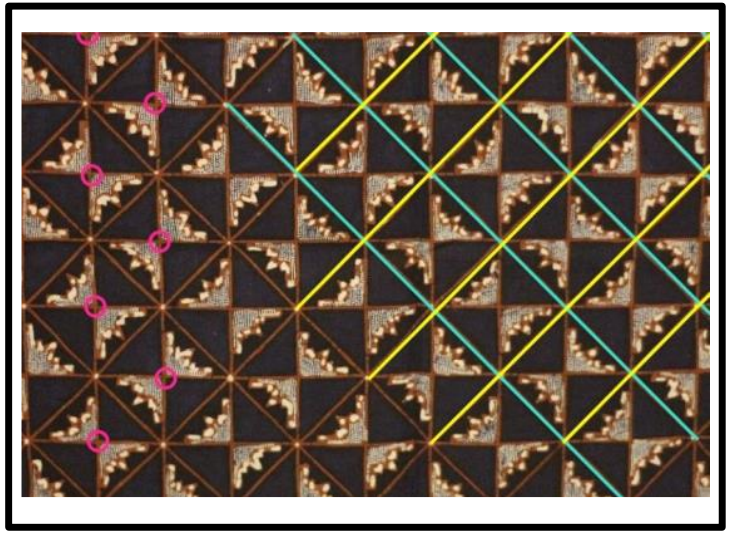

Gambar 7. Analisis Simetri Batik Slobog

\section{B. Filosofi Batik}

Selain pola simetri, sebelas batik yang dianalisis pada bagian sebelumnya juga memiliki makna filosofis. Makna filosofis batik-batik tersebut terkait dengan penggunaannya dalam upacara tradisi. Berikutnya, kami akan memaparkan makna filosofis batik-batik tersebut berdasarkan kronologis pemakaiannya.

Dua batik digunakan pada saat upacara ketika pemakainya menginjak usia remaja. Kedua batik tersebut adalah batik Parang Pamor dan batik Parang Canthel. Batik Parang Pamor dikenakan anak laki-laki pada saat upacara khitanan. Dengan mengenakan batik ini, anak tersebut diharapkan akan memiliki pamor atau kepribadian yang baik. Batik Parang Canthel dikenakan oleh anak perempuan ketika haid pertamanya dengan harapan agar anak tersebut cepat kecanthel atau lekas mendapatkan jodoh.

Empat batik digunakan pada saat upacara pernikahan. Keempat batik tersebut adalah Nithik Cakar, Ceplok Satriya Wibawa, Truntum, dan Wirasat. Batik Nithik Cakar digunakan oleh ibu pengantin ketika melakukan upacara permandian sebelum acara pernikahan. Batik ini melambangkan harapan agar pengantin kelak diberikan kemudahan dalam mencari nafkah. Batik Ceplok Satriya Wibawa digunakan oleh calon pengantin pria menjelang upacara pernikahan dengan harapan agar dia memiliki sifat ksatria dan penuh dengan wibawa. Batik Truntum dan 
Wirasat digunakan oleh orang tua atau mertua pengantin pada saat upacara pernikahan. Batik Truntum melambangkan berkumpulnya dua keluarga yang selalu dipenuhi dengan cinta, sedangkan batik Wirasat melambangkan harapan agar senantiasa diberikan petunjuk oleh Tuhan Yang Maha Esa.

Empat batik berikutnya digunakan ketika upacara tujuh bulan kehamilan. Empat batik tersebut adalah Sidamukti, Sidaasih, Sidamulya, dan Lurik Yuyu Sekandang. Batik Sidamukti melambangkan kebahagiaan, baik untuk ibu maupun bayi yang akan dilahirkan. Batik Sidaasih melambangkan kasih sayang. Batik Sidamulya melambangkan kemuliaan baik bagi ibu ataupun bayi. Terakhir, batik Lurik melambangkan harapan agar ibu memiliki mendapat banyak keturunan.

Batik terakhir digunakan pada saat upacara duka, yaitu batik Slobog. Batik ini melambangkan harapan bagi orang yang meninggal dan orang-orang yang ditinggalkannya. Bagi orang yang meninggal, batik ini menggambarkan harapan agar orang tersebut mendapatkan jalan yang lapang menuju tempat di sisi Tuhan Yang Maha Esa. Bagi orang-orang yang ditinggalkan, batik ini menggambarkan harapan agar orangorang tersebut diberikan hati yang lapang atau ikhlas.

Makna filosofis batik-batik tersebut akan memberikan arti yang lebih kaya jika makna-makna tersebut dipasangkan dengan pola-pola simetrinya. Tabel 1 berikut menyajikan daftar pola-pola simetri yang dimiliki oleh 11 batik dalam penelitian ini beserta dengan makna-makna filosofisnya.

Tabel 1.

Pola Simetri dan Makna Filosofis Batik

\begin{tabular}{cll}
\hline $\begin{array}{c}\text { Pola } \\
\text { Simetri }\end{array}$ & \multicolumn{1}{c}{ Batik } & Makna Filosofis \\
\hline$p 1$ & Wirasat, & Petunjuk Tuhan \\
& Sidamukti, & YME; kebahagiaan; \\
& Sidaasih, & kasih sayang; \\
& Sidamulya & kemuliaan \\
\hline$p 2$ & Parang Pamor & Kepribadian baik; \\
& dan Parang & lekas mendapat \\
& Canthel & jodoh \\
\hline$p 4 m$ & Nitik Cakar, & Kemudahan \\
& Ceplok Satriya & mencari nafkah; \\
& Wibawa, & ksatria dan \\
& Truntum, Lurik & berwibawa; \\
& Yuyu Sekandang & berkumpulnya \\
& & keluarga dan \\
& & penuh cinta \\
\hline$p g g$ & Slobog & Lapang atau ikhlas \\
\hline
\end{tabular}

\section{Pembahasan}

Penelitian ini telah menunjukkan pola simetri dan makna filosofis 11 batik Keraton Yogyakarta yang digunakan dalam upacara tradisi. Motif batik-batik tersebut masuk ke dalam kategori pola simetri $p 1, p 2, p 4 m$, atau pgg. Lebih lanjut, 11 batik tersebut memiliki makna filosofisnya masing-masing berdasarkan kapan batik-batik itu digunakan dalam upacara tradisi.

Dari sudut pandang pembelajaran matematika, hasil penelitian ini paling tidak dapat digunakan sebagai konteks dalam tugas, permasalahan, ataupun materi matematika, khususnya dalam topik transformasi geometri (Leikin et al., 2000; Manuel et al., 2015; Trinick et al., 2017). Konteks seperti ini penting bagi peserta 
didik dalam belajar matematika karena konteks tersebut dapat menghubungkan materi yang akan dipelajari dengan pengetahuan mereka sebelumnya dan meningkatkan motivasi belajar mereka (Gravemeijer \& Doorman, 1999; Sawatzki et al., 2019; Sari \& Afriansyah, 2020). Hasilnya, penggunaan konteks yang tepat akan membantu peserta didik mencapai hasil belajar yang optimal (Hoogland et al., 2018; Van den Heuvel-Panhuizen, 2005; Zbiek \& Conner, 2006; Lisnani, 2019).

Teknologi dapat digunakan untuk memfasilitasi peserta didik mempelajari matematika dengan menggunakan konteks budaya. Karena penelitian ini fokus pada pola simetri, perangkat lunak geometri dinamis, seperti Desmos, potensial untuk mengajak peserta didik melakukan matematika melalui aktivitas-aktivitas interaktif (Kristanto, 2018, 2019). Perangkat lunak tersebut dapat menyediakan lingkungan belajar sosial yang kreatif bagi peserta didik untuk menyelidiki matematika melalui budaya (Meyer, 2020).

Hasil kajian etnomatematika di penelitian ini juga berpotensi untuk memberikan koneksi unik antara matematika dan kebudayaan. Pembelajaran matematika yang disesuaikan dengan pengetahuan budaya, pengalaman awal, dan kerangka acuan peserta didik akan membuat matematika menjadi lebih dekat dan bermakna ke peserta didik (Orey \& Rosa, 2020). Pembelajaran matematika yang relevan terhadap kebudayaan peserta didik seperti ini akan meningkatkan kualitas pembelajaran mereka (Rosa \& Orey, 2015; Nanang \& Sukandar, 2020). Misalnya, penggunaan batik Surakarta dalam pembelajaran matematika di Indonesia akan mengenalkan peserta didik akan kekayaan budaya bangsa dan relevansinya terhadap matematika yang mereka pelajari.

Dari sudut pandang kajian etnomatematika, penelitian ini memberikan wawasan-wawasan yang berharga dalam mengaitkan aspek-aspek matematika dan budaya. Misalnya, hasil penelitian ini akan menambah kajian budaya dari sudut pandang desain dan geometri yang sebelumnya telah banyak dilakukan oleh para peneliti lain(Dewita et al., 2019; Mulyani \& Natalliasari, 2020; Muslim \& Prabawati, 2020).

Terakhir, meskipun sangat terbatas, penelitian ini juga telah menawarkan kemungkinan adanya hubungan antara pola simetri dalam batik dan makna filosofisnya. Hubungan seperti ini,jika dapat dieksplorasi lebih mendalam, akan menyumbangkan pengetahuan yang berharga pada bidang antropologi(D. Washburn, 1999), psikologi (D. Washburn \& Humphrey, 2001), ataupun bidangbidang lainnya.

\section{Penutup}

Penelitian ini memiliki motivasi untuk memberikan hasil kajian etnomatematika terhadap batik Keraton Surakarta dengan 
menggunakan analisis simetri. Penelitian ini mendapatkan pola-pola simetri yang dimiliki oleh 11 batik. Pola-pola simetri tersebut adalah p1, p2, p4m, dan pgg. Selain itu, penelitian ini juga telah menyelidiki makna-makna filosofis batikbatik tersebut. Kedua hal tersebut dapat memberikan kontribusi pedagogis kepada pembelajaran matematika, khususnya terkait dengan topik transformasi geometri.

Ketika memaknai hasil penelitian ini, kami mengharapkan agar pembaca menyadari keterbatasan dari penelitian ini. Pertama, kami menyadari bahwa data yang digunakan dalam penelitian ini dapat diperkaya lagi untuk mendapatkan kesimpulan yang lebih kuat. Kedua, kami belum bisa membuat kesimpulan mengenai hubungan antara pola-pola simetri yang ditemukan di dalam batik dengan makna filosofisnya. Pembaca dapat menyelidiki lebih lanjut hubungan tersebut dengan menggunakan desain penelitian yang ketat.

\section{UCAPAN TERIMA KASIH}

Kami mengucapkan terima kasih kepada semua pihak yang telah mendukung penyelesaian artikel ini, khususnya pada semua penelaah atas umpan balik yang konstruktif demi semakin baiknya artikel ini.

\section{Daftar PUStaka}

'Adna, S. F., Nasution, N. B., \& Mardhiyana, D. (2020). Numbers sequence in batik
Jlamprang motif of Pekalongan. Journal of Physics: Conference Series, 1663, 012011.

Albanese, V., Adamuz-Povedano, N., \& Bracho-López, R. (2017). The Evolution of Ethnomathematics: Two Theoretical Views and Two Approaches to Education. In M. Rosa, L. Shirley, M. E. Gavarrete, \& W. V. Alangui (Eds.), Ethnomathematics and its Diverse Approaches for Mathematics Education (pp. 307328).

Barton, B. (1996). Making sense of ethnomathematics:

Ethnomathematics is making sense. Educational Studies in Mathematics, 31(1-2), 201-233.

Chao, G. T., \& Moon, H. (2005). The Cultural Mosaic: A Metatheory for Understanding the Complexity of Culture. Journal of Applied Psychology, 90(6), 1128-1140.

Crowe, D. J. (2004). Introduction to the plane symmetries. In D. K. Washburn \& D. W. Crowe (Eds.), Symmetry Comes of Age: The Role of Pattern in Culture (pp. 3-17). University of Washington Press.

D’Ambrosio, U. (2012). The program ethnomathematics: Theoretical basis and the dynamics of cultural encounters. Cosmopolis, a Review of Cosmopolitics, 3-4, 13-41.

Dewita, A., Mujib, A., \& Siregar, H. (2019). Studi Etnomatematika tentang Bagas Godang sebagai Unsur Budaya Mandailing di Sumatera Utara. Mosharafa: Jurnal Pendidikan Matematika, 8(1), 1-12.

Faiziyah, N., Khoirunnisa', M., Azizah, N. N., Nurrois, M., Prayitno, H. J., Desvian, 
Rustamaji, \& Warsito. (2021). Ethnomathematics: Mathematics in Batik Solo. Journal of Physics: Conference Series, 1720, 012013.

Garnadi, A. D., Guritman, S., Kusnanto, A., \& Hanum, F. (2012). Survey Pola Grup Kristalogi Bidang Ragam Batik Tradisional. Journal of Mathematics and Its Applications, 11(2), 1.

Gravemeijer, K., \& Doorman, M. (1999). Context Problems in Realistic Mathematics Education: A Calculus Course as an Example. Educational Studies in Mathematics, 39, 111-129.

Hoogland, K., de Koning, J., Bakker, A., Pepin, B. E. U., \& Gravemeijer, K. (2018). Changing representation in contextual mathematical problems from descriptive to depictive: The effect on students' performance. Studies in Educational Evaluation, 58, 122-131.

Kristanto, Y. D. (2018). Modul Guru: Mengupayakan Diskursus dan Penalaran Matematis dengan Desmos. Figshare.

Kristanto, Y. D. (2019). Creating Interactive and Mathematically Rich Activity with Desmos. Figshare.

Leikin, R., Berman, A., \& Zaslavsky, O. (2000). Learning through teaching: The case of symmetry. Mathematics Education Research Journal, 12(1), 18-36.

Lisnani, L. (2019). Pengaruh Penggunaan Konteks Daun terhadap Hasil Belajar Siswa. Mosharafa: Jurnal Pendidikan Matematika, 8(3), 423-434.

Lisnani, L., Zulkardi, Z., Putri, R. I. I., \& Somakim, S. (2020). Etnomatematika: Pengenalan Bangun Datar Melalui Konteks Museum Negeri Sumatera
Selatan Balaputera Dewa. Mosharafa: Jurnal Pendidikan Matematika, 9(3), 359-370.

Manuel, H., Hāwera, N., \& Taylor, M. (2015). Transformation geometry: Mā te nekehanga, mā te whakaata, mā te hurihanga. In R. Averill (Ed.), Mathematics and Statistics in the Middle Years: Evidence and Practice (pp. 131-145). NZCER Press.

Maulidya, T. I., \& Sihombing, R. V. (2018). Pola Kristalografi Bidang Ragam Batik di Yogyakarta. Prosiding Sendika, 8298.

Meyer, D. D. (2020). Social and Creative Classrooms. Mathematics Teacher: Learning and Teaching PK-12, 113(3), 249-250.

Miles, M. B., Huberman, A. M., \& Saldana, J. (2014). Qualitative Data Analysis: A Methods Sourcebook (3rd ed.). SAGE.

Mulyani, E., \& Natalliasari, I. (2020). Eksplorasi Etnomatematik Batik Sukapura. Mosharafa: Jurnal Pendidikan Matematika, 9(1), 131142.

Muslim, S. R., \& Prabawati, M. N. (2020). Studi Etnomatematika terhadap Para Pengrajin Payung Geulis Tasikmalaya Jawa Barat. Mosharafa: Jurnal Pendidikan Matematika, 9(1), 59-70.

Nanang, N., \& Sukandar, A. (2020). Meningkatkan Kemampuan Siswa SDIT Miftahul Ulum Pada Operasi Bilangan Bulat Melalui CAIContextual. Mosharafa: Jurnal Pendidikan Matematika, 9(1), 71-82.

Orey, D. C., \& Rosa, M. (2020). Positionality and Creating Dialogue in Nepal: Connecting Ethnomathematics and Modelling - the Importance of Place Through Ethnomodelling. Social 
Inquiry: Journal of Social Science Research, 2(1), 82-103.

Pujiyanto, P. (2013). Fenomena Desain Batik Surakarta dan Yogyakarta. Gelar: Jurnal Seni Budaya, 11(1), 68-86.

Rosa, M., \& Gavarrete, M. E. (2017). An Ethnomathematics Overview: An Introduction. In M. Rosa, L. Shirley, M. E. Gavarrete, \& W. V. Alangui (Eds.), Ethnomathematics and its Diverse Approaches for Mathematics Education (pp. 3-19). Springer.

Rosa, M., \& Orey, D. C. (2015). Ethnomathematics: connecting cultural aspects of mathematics through culturally relevant pedagogy. Mathematics Education \& Society, 8(3), 887-897.

Sandelowski, M. (2000). Whatever happened to qualitative description? Research in Nursing \& Health, 23(4), 334-340.

Sari, H. M., \& Afriansyah, E. A. (2020). Analisis Miskonsepsi Siswa SMP pada Materi Operasi Hitung Bentuk Aljabar. Mosharafa: Jurnal Pendidikan Matematika, 9(3), 439-450.

Sawatzki, C., Downton, A., \& Cheeseman, J. (2019). Stimulating proportional reasoning through questions of finance and fairness. Mathematics Education Research Journal, 31(4), 465-484.

Trinick, T., Meaney, T., \& Fairhall, U. (2017). Cultural and Mathematical Symmetry in Māori Meeting Houses (Wharenui). In M. Rosa, L. Shirley, M. E. Gavarrete, \& W. V. Alangui (Eds.), Ethnomathematics and its Diverse Approaches for Mathematics Education (pp. 235-255). Springer.

UNESCO. (2009). Decision of the
Intergovernmental Committee: 4.COM 13.44.

Van den Heuvel-Panhuizen, M. (2005). The Role of Contexts in Assessment Problems in Mathematics. For the Learning of Mathematics, 25(2), 2-9.

Washburn, D. (1999). Perceptual Anthropology: The Cultural Salience of Symmetry. American Anthropologist, 101(3), 547-562.

Washburn, D., \& Humphrey, D. (2001). Symmetries in the Mind: Production, Perception, and Preference for Seven One-Dimensional Patterns. Visual Arts Research, 27(2), 57-68.

Zbiek, R. M., \& Conner, A. (2006). Beyond Motivation: Exploring Mathematical Modeling as A Context for Deepening Students' Understandings of Curricular Mathematics. Educational Studies in Mathematics, 63(1), 89112.

\section{Riwayat Hidup PenUlis}

\section{Maria Glory Astriandini}

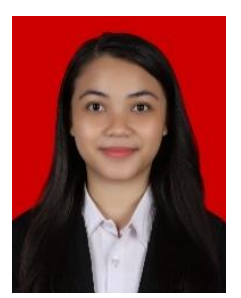

Lahir di Tiuh Balak Pasar, 24 Desember 1998. Studi S1 di program studi Pendidikan Matematika Universitas Sanata Dharma, Yogyakarta, lulus tahun 2020.

\section{Yosep Dwi Kristanto}

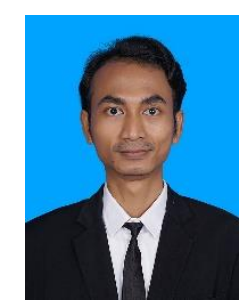

Lahir di Banyuwangi, 24 Maret 1990. Pendidikan S1-nya diselesaikan pada tahun 2012 di Universitas Negeri Malang dan pendidikan S2-nya diselesaikan pada tahun 2015 di Universitas Negeri Surabaya. Bidang penelitian yang diminatinya adalah pendidikan matematika dan statistika, teknologi pendidikan, dan desain pembelajaran. 